\title{
Design of A NEMS Cantilever Sensor for Explosive Detection
}

\author{
P.V.T.Lokesh Kumar, P.H.S Tejomurthy, Dharmireddy Ajay Kumar
}

\begin{abstract}
The particular recognition of explosives in countering fear monger dangers and follow explosives has turned into an appallingly progressed and expensive exertion. This happens because of different impacts, similar to the extensive broad assortment of materials which will be used as explosives, the deficiency of basically perceivable marks, and the monstrous assortment of roads by these weapons might be sent and consequently there will be absence of shoddy sensors with high sensitivity and low vapor analyte property. High sensitivity and property joined with the power, to cut down the orchestrating cost of sensors. Misuse age is basic in winning the war an explosives based demonstration of psychological warfare. Nanosensors can possibly satisfy every one of the necessities of an effective stage for the follow identification explosives. Enhance the sensitivity and selectivity of NEMS cantilever for piezo resistive material in Humidity conditions and manufacture Rectangular Shape Omni directional NEMS cantilever cheap IC and Characteristic chip with Real time reenactment utilizing omnicant.
\end{abstract}

keywords: NEMS, High Sensitivity, low vapor analyte, selectivity.

\section{INTRODUCTION}

As the title of this task recommends, this examination centers around the two perspectives, i.e. the utilization of piezoresistive cantilevers in static and dynamic detecting. The displayed work expects to lift the execution of piezoresistive cantilevers in situations where the yield flag is either DC (e.g., strain measures) or an AC (e.g., thunderous sensors) signal[1]. The piezoresistive cantilever is a standout amongst the most prominent transducers, which interprets information from the mechanical space into the electrical area, e.g. the measure of power applied on the cantilever into an obstruction change to the cantilever into a reverberation recurrence change.

\section{A. Explosive Follow Identifiers}

As a rule, unstable based psychological warfare has developed greatly since dangerous based weapons are anything but difficult to deploy[4], basic and can cause huge harm identifying explosives. It is a testing errand on account of various issues, for example, the low hage weights out from ultimate detonator, visit

Revised Manuscript Received on August 20, 2019.

P.V.T Lokesh Kumar*, M.Tech, VLSI, E.C.E Department, Sir C.R.R College of Engineering, Eluru, A.P.

Dr.P.H.S Tejomurthy, Professor, E.C.E Department, Sir C.R.R College of Engineering, Eluru, A.P.

Dharmireddy Ajay Kumar , Assistant Professor, E.C.E Department, Sir C.R.R College of engineering, Eluru, A.P
1. Gather waft as a consequence impure examples in distinction to over in other words resting on expressive speculated question;

2. Expressive unstable particles resting on a sorbet material are pre concentrated;

3. The particles discharged from the pre concentrator are adsorbed for location on a flag transduction sensor component;

4. Break down, describe, and report the information. Integral to location is substance acknowledgment utilizing a particular operator and flag transduction.

The most vital execution attributes of follow dangerous of sensors are including high affectability, selectivity, reversibility, and constant task.

\section{DESIGN OF PIEZORESISTIVE CANTILEVER}

NEMS cantilever sensor depends on redirection of the cantilever pillar. At the point when stack is connected on the cantilever, the focused on components are twisted. The NEMS cantilever will bend[3]. At the point when twisting happens, focuses on structure and shape uproot. At the free end or along the NEMS cantilever surface when it stacked the disfigurement happens. Ordinarily stacking is a power or mass that is appended to the NEMS cantilever which makes the NEMS cantilever twist. As the NEMS cantilever avoids, the came about twisting is named bowing. An outer connected load which causes twisting will result in responses at the free end, comprising of dislodging or redirection.

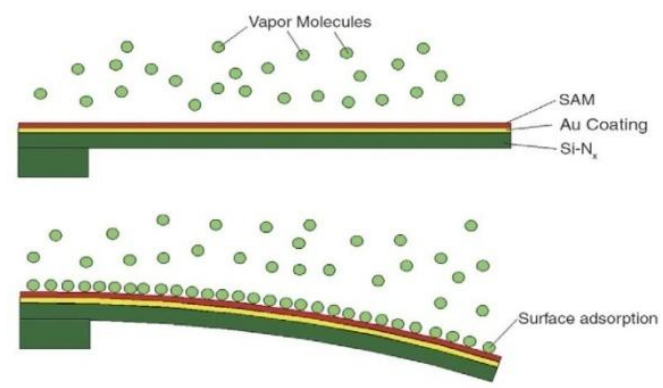

Fig.1.Outline demonstrating sub-atomic adsorption-prompted bowing of a cantilever shaft emerging from various adsorption.

The cantilever bowing happens as the after effect of applying a point compel on the pillar free end is portrayed at a point along the cantilever length, the cantilever diversion on the cantilever tip, can be computed as[1]

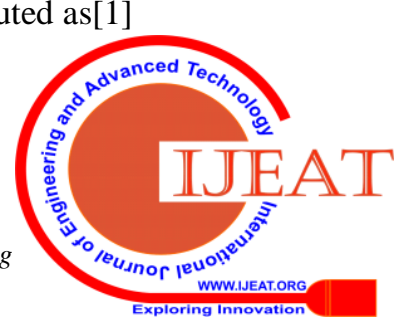




\section{Design of A NEMS Cantilever Sensor for Explosive Detection}

$$
\delta=\frac{\mathrm{aL}(1-\mathrm{w})}{\mathrm{Et}^{2}}\left(\sigma_{1}-\sigma_{2}\right)
$$

where

$\mathrm{L}$ is length $\mathrm{t}$ is the thickness

$\mathrm{V}$ is Poisson proportion, $\mathrm{E}$ is young Module

$\delta$ is an avoidance, $\sigma$ is a pressure

Table-I: Definition of execution

\begin{tabular}{|c|c|c|}
\hline & Single layer & Double layer \\
\hline Material & $\mathrm{Si}$ & Gold \\
\hline Length & $150 \mathrm{~nm}$ & $150 \mathrm{~nm}$ \\
\hline Thickness & $10 \mathrm{~nm}$ & $10 \mathrm{~nm}$ \\
\hline Poisson Ratio & 0.28 & 0.42 \\
\hline Young's module & $170 \mathrm{e} 9$ & $76 \mathrm{e} 9$ \\
\hline Deflection & $\begin{array}{c}3.278 \times \\
10-12\end{array}$ & $0.1487 \times 10-12$ \\
\hline
\end{tabular}

The difference in obstruction with strain is halfway because of geometrical changes in the distorted body and mostly because of physical changes inside the material itself. Together these two impacts are depicted by the[10]strain measure factor $\gamma$

$$
\gamma=\frac{\Delta R}{\frac{\vec{R}_{0}}{a_{\varepsilon}}}=(1+2 V)+\frac{a_{f}}{\frac{x_{0}}{a_{\varepsilon}}}
$$

Where Ro is the underlying opposition,

$\Delta \mathrm{R}=\mathrm{R}-\mathrm{R}$ is the opposition change coming about because of the strain change,

$v$ is the Poisson's proportion, and

$\rho o$ and $\Delta \rho$ are the electrical resistivity and the difference in resistivity coming about because of $\Delta \rho$, individually.

The mass of water vapor in certain volume is characterized as Absolute Humidity. At the point when perfect gas is considered, the supreme stickiness is figured by

$$
\mathrm{A}=\mathrm{C} \cdot \frac{\mathrm{PW}}{\mathrm{T}}\left(\mathrm{g} / \mathrm{m}^{3}\right)
$$

\section{Where $\mathrm{c}=$ constant $2.16679 \mathrm{gk} / \mathrm{j}$}

$\mathrm{Pw}=$ vapor pressure in $\mathrm{pa}$

$\mathrm{T}=$ Temperature in At that point, the stress can be calculated[6] to be:

$$
\sigma_{\max }=\left(\frac{6 L}{W t^{2}}\right) F=\left(\frac{a E t}{2 L^{2}}\right)
$$

Where,

$\mathrm{F}$ is the applied force and

$\mathrm{W}$ is the width of the cantilever beam

The resulting fractional resistance change is given by[10]:

$$
\frac{\Delta R}{R}=\pi_{l} \sigma_{\max }
$$

Where, $\pi l$ is the longitudinal piezoresistive coefficient of the material.

Table 1 demonstrates ordinarily utilized sensor execution qualities. Follow dangerous location requires to a great degree high affectability and low points of confinement of identification (LODs) in light of the moderately modest number of atoms that can be gathered thus.

Table-II: Vapor weights and atomic weights Exterior

\begin{tabular}{|c|c|}
\hline $\begin{array}{c}\text { Executio } \\
\text { n parameter }\end{array}$ & Definition \\
\hline Sensitivity & $\begin{array}{c}\text { The incline of an adjustment bend of progress in unit } \\
\text { analyte fixation Selectivity. }\end{array}$ \\
\hline Selectivity & $\begin{array}{c}\text { The capacity to distinguish a particular analyte within } \\
\text { the sight of other meddling atoms. }\end{array}$ \\
\hline $\begin{array}{c}\text { Reaction } \\
\text { time }\end{array}$ & $\begin{array}{c}\text { The space appropriate directed toward react indistnction } \\
\text { to zero alate focus directed toward a stage now affecting } \\
\text { fixation. }\end{array}$ \\
\hline Linearity & $\begin{array}{c}\text { Expressive run where the sensor reaction abide insidious } \\
\text { degree to the alate fixation. }\end{array}$ \\
\hline Hysteresis & Expressive capability in sensor attributes. \\
\hline
\end{tabular}

Constantly regular explosives have to a great degree low haze weights at surrounding temperature.

Table 2 demonstrates the vapor weights of normal explosives. The specific low vapor weights show that these particles are to a great degree sticky and have a tendency to adsorb to surfaces effortlessly. It ought to be noticed that the vapor weights of explosives increase quickly with temperature[5]. Dangerous vapors made by warming an example consolidate quickly on cooler of a few explosives based adsorption will be higher on superficial with a high shallow energy, for example, metals, noble metal, and so forth. Contrasted and low surface vitality materials, for example,

polymers, plastics, and so forth. The buildup of the atoms in conveyance lines into sensor frameworks is additionally caused because of the sticky idea of ammunition particles on surface at room temperature. In this manner, follow inspecting of these groups of ammunitions with less haze weights is a testing issue due to the modest number of particles in an examining volume[9].

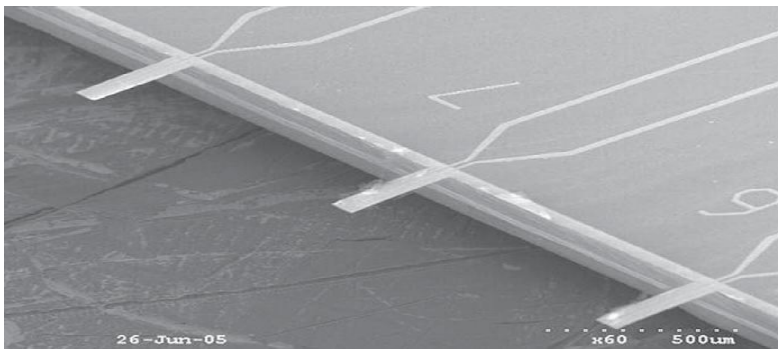

\section{FEM SIMULATION}

\section{A. Nanomechanical Sensor Stage:}

There are numerous methods of activity for Nanomechanical sensors, for example, cantilever bar. For instance, the mass adsorption of a cantilever bar shifts with reverberation recurrence. 
Nanocantilevers-indicate high affectability to mass adsorption[12]. Cantilevers with low spring constants (low reverberation recurrence) cantilevers are normally nanofabricated from si utilizing ordinary photograph.

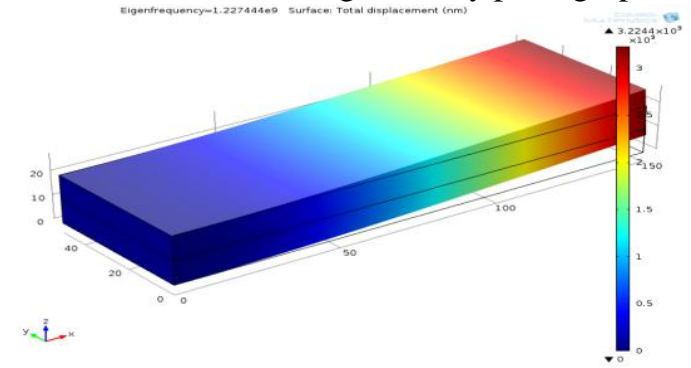

Fig.2. Double layer nano cantilever FEM Response

covering and drawing methods. Commonly measurements of a cantilever can fluctuate from $150 \mathrm{~nm}$ to few nanos long, contingent upon the method of operation[17].

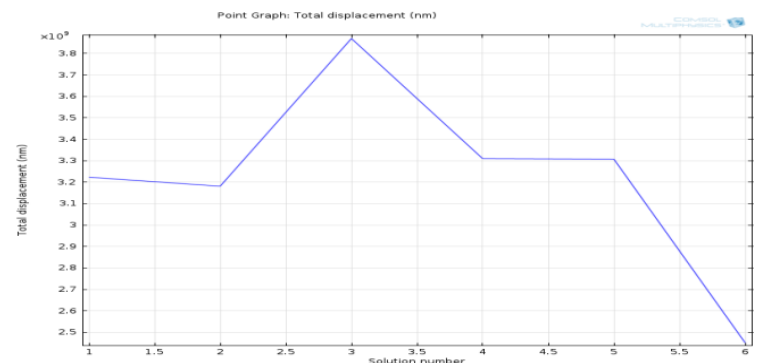

Fig.3. FEM of a piezoresistive nanocantilever array.

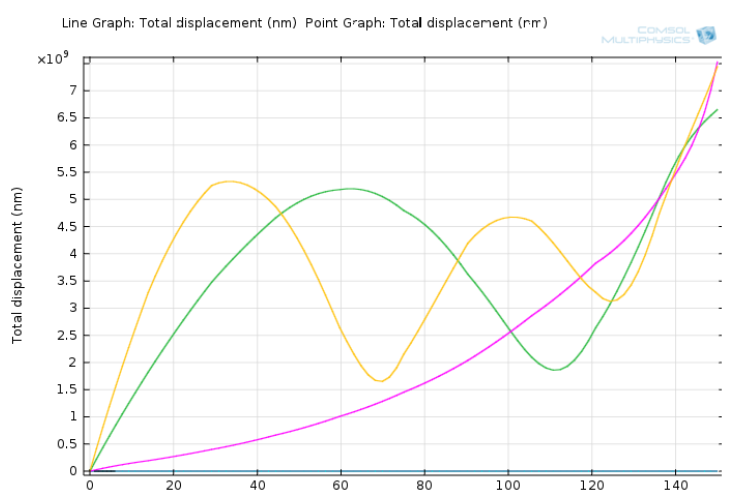

Fig.4. Line graph of double layer

\section{EXPERIMENTAL RESULTS}

The si piezoresistive cantilever creation method created by Bolaen's gathering produces cantilever with high affectability, low electron commotion and little float Fig. demonstrates a filtering electron microimage of a piezoresistive cantilever bunch. The piezoresistive readout technique is downsized and flawless with electronic packaging[13]. The differential contorting response of a piezoresistive cantilever column secured with gold concerning an uncoated cantilever when exhibited to dynamite hazes.

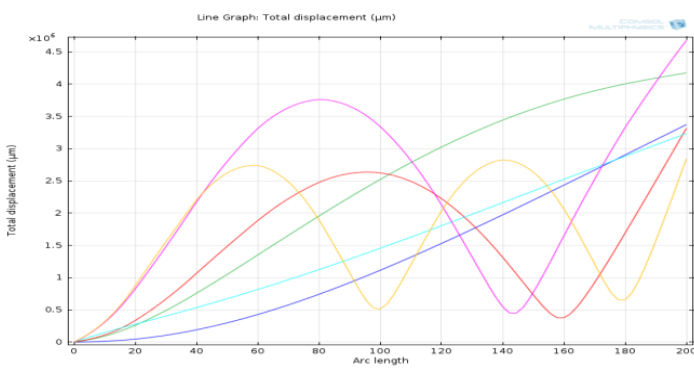

Fig.5. checking electron microimage of a piezoresistive nanocantilever exhibit. Beam bowing from submonolayer inclusion of adsorbed particles can be distinguished.

The six cantilevers of reaction examples can be covered with an alternate SAM when presented to vapors of TNT, ethanol, Acetone at 30 PPM, and CH32CO at 20 PPM. Every segment demonstrates the $80 \mathrm{~s}$ bowing reaction of one cantilever/covering (si with gold poly-si with gold) when presented to every one of the four analyte.

Table-III: deflection of double layer gold (4- MBA) and single layer silicon.

\begin{tabular}{|c|c|c|}
\hline $\begin{array}{c}\text { Silicon with 4-MBA } \\
\text { (gold) material }\end{array}$ & $\begin{array}{c}\text { Double layer } \\
\text { coated material }\end{array}$ & $\begin{array}{c}\text { Double layer } \\
\text { uncoated material }\end{array}$ \\
\hline Deflection & $3.278 \times 10-12$ & $\begin{array}{c}1.287 \times \\
10-11\end{array}$ \\
\hline Humidity & $0.148 \times 10-12$ & $\begin{array}{c}1.881 \times \\
10-6\end{array}$ \\
\hline Sensitivity & $6.827 \times 10-12$ & $\begin{array}{c}5.712 \times \\
10-6\end{array}$ \\
\hline
\end{tabular}

Table -IV: deflection and sensitivity of double layer silicon

\begin{tabular}{|c|c|c|}
\hline Detonator & $\begin{array}{c}\text { Sub-atomic } \\
\text { weight(g/mol) }\end{array}$ & $\begin{array}{c}\text { Haze weight in } \\
\text { the vicinity of 200c } \\
\text { (Torr) }\end{array}$ \\
\hline $\begin{array}{c}\text { (CH3)2CO } \\
\text { ne-6-trinitrotolue (TNT) }\end{array}$ & 58.08 & $3.3 \times 10-3$ \\
\hline $\begin{array}{c}\text { Tetranitro-triazacy } \\
\text { clohexane (RDX) }\end{array}$ & 227.1 & $4.8 \times 10-6$ \\
\hline si & 222.3 & Sold \\
\hline
\end{tabular}

Fig.6. Divergent bowing reaction of a piezoresistive cantilever beam covered with a gold practical layer.

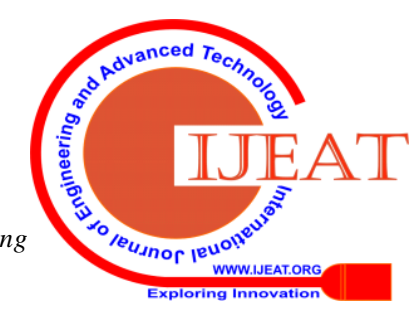




\section{Design of A NEMS Cantilever Sensor for Explosive Detection}

Dissimilar bowing reaction of a piezo-resistive beam gold covered material is presented to the dynamite haze. The gadget is presented to dynamite for a brief period pursued by a pursue of dry nitrogen, this delivers the reaction crest appeared in Fig. followed[11] by a desorption period amid which the adsorbed material is expelled by the nitrogen, leaving the gadget prepared to recognize another analyte[8]. Since the cantilever coatings are just halfway specific. The introduction of the cluster to all analyte is led in indistinguishable way from depicted above for dynamite

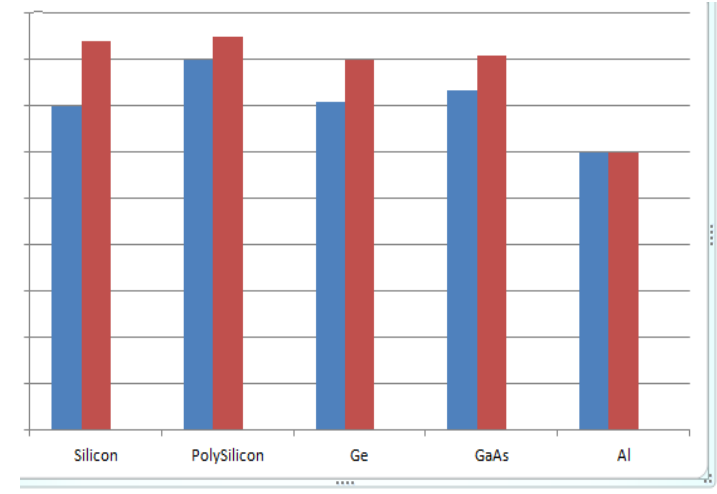

Fig.7. Deflection and humidity for different materials

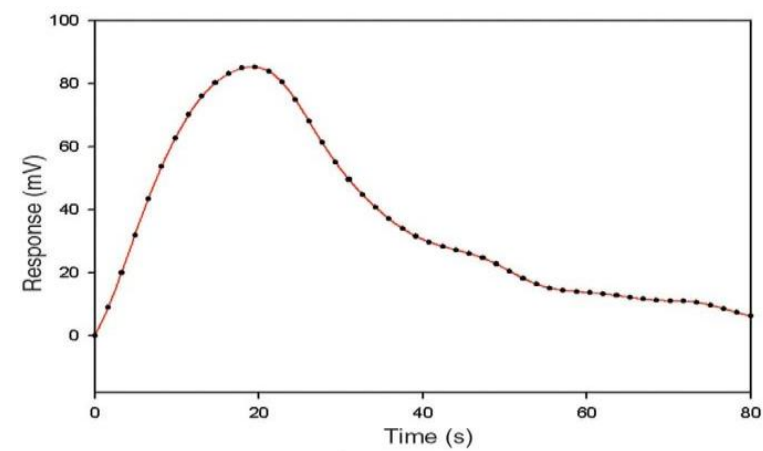

Fig.8. Divergent bowing reaction of a piezo resistive beam covered with a gold/4- mercapto benzoic acid useful layer.

Deflection and humidity requires numerous difficulties to be survived. To a great degree low vapor weights limit[9] the quantity of hazardous atoms that can be gathered in a sensible identification time. Shows table deflection and humidity of different material. Show Fig.9 Sensitivity and Temprature for Acetone concentration 50 PPM[13] of 4-MBA(mercapto benzoic acid) and TNT, Ethanol, RDX

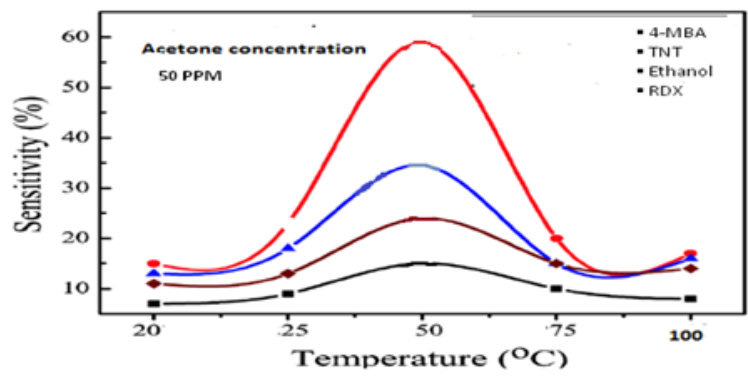

Fig.9.The chart portrayal of silicon with 4-MBA material redirection affectability and temperature
The device revealed to $\mathrm{CH} 32 \mathrm{CO}$ for a brief period seen by methods for a float away from trinitarian. Creates the reaction soaring saw through distortion term amid that the adsorbed fabric is disposed of through the nitrogen, residue with apparatus arranged to find another analyte precedent TNT, RDX[15].

Table-V: Humidity based deflection in different material cantilever beam response

\begin{tabular}{|c|c|c|}
\hline Material & $\begin{array}{c}\text { Deflection at } \\
\mathbf{7 0 \%} \text { humidity }\end{array}$ & $\begin{array}{c}\text { Deflection at } \\
\mathbf{8 0 \%} \text { humidity }\end{array}$ \\
\hline $\mathrm{Si}$ & $1.429 \times 10-8$ & $1.546 \times 10-8$ \\
\hline Poly silicon & $1.645 \times 10-8$ & $1.824 \times 10-8$ \\
\hline $\mathrm{Ge}$ & $2.424 \times 10-8$ & $2.917 \times 10-8$ \\
\hline $\mathrm{GaAs}$ & $2.711 \times 10-8$ & $3.521 \times 10-8$ \\
\hline $\mathrm{Al}$ & $3.133 \times 10-8$ & $4.214 \times 10-8$ \\
\hline
\end{tabular}

For the reason that cantilever coatings are best to a limited extent particular, a cluster location without exception stanchion endure covered upon a restrictive specific covering abide required as long as stipulation. The reaction from a variety of cantilevers fixed with silicon and 4-MBA particular coatings. PVP with $\mathrm{CH} 3$ )2CO has additional affectability dependent on a variation in physical detecting material underneath fuel presentation.

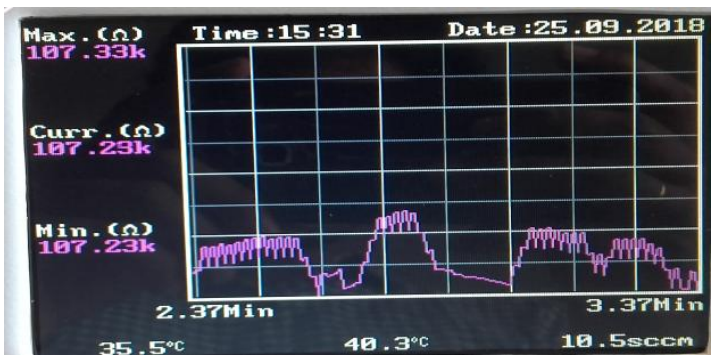

Fig.10. Omnicant result for PVP with acetone.

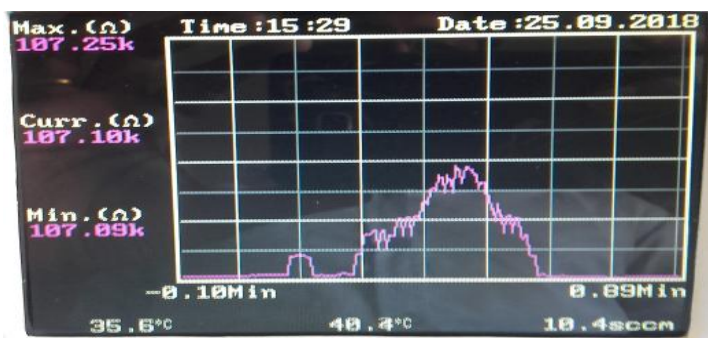

Fig.11. Omnicant result for 4-MBA with acetone.

The affectability is typically depicted on the grounds that the proportion of the opposition of the detecting component inside the objective gas to that in air. The affectability is particularly relying upon cantilever measurements 【20】^0 c vapor strain the hazardous experiences thermally[16] expedited decay 


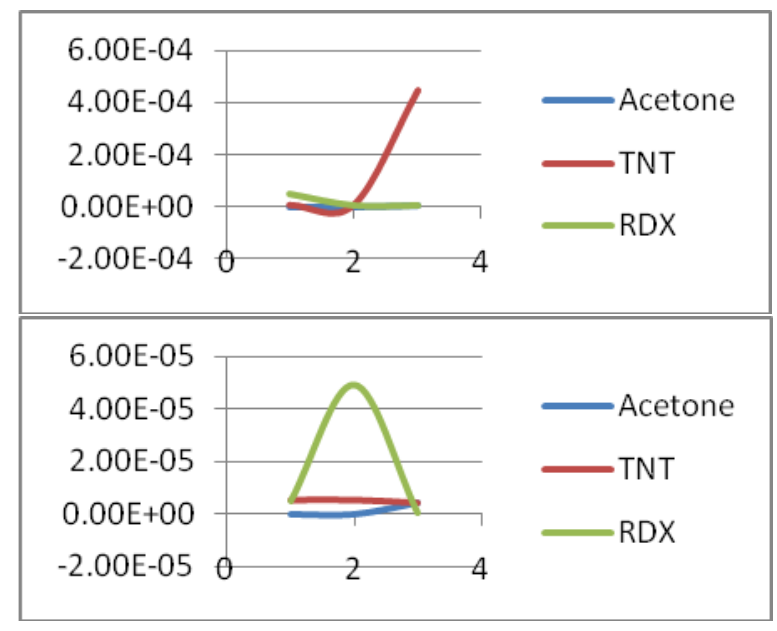

Fig.12. Graphical representation of silicon and polysilicon cantilever beam with different analytes sensitivity at $80 \%$ humidity

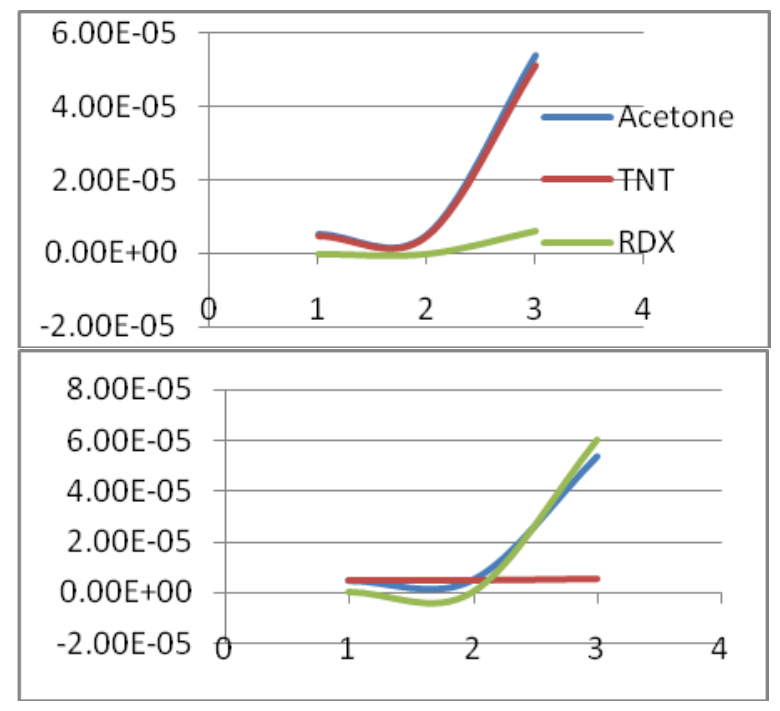

Fig.13.The chart portrayal of twofold layer cantilever barsilicon with gold and poly silicon with gold material distinctive low vapor analytes affectability at $80 \%$ stickiness

Follow touchy identification with high affectability and selectivity is a of touchy atoms that can be gathered in sensible time absence of selectivity due to obstruction from different particles is clearing a reasonable way to the improvement of nanosensors. formidablechallenge due to various operational elements, for example, the intense deficiency.

\section{CONCLUSION}

Nanoscale impacts can be abused to the offer the likelihood of sensors that fulfill every one of the necessities for follow dangerous location. Nanosensors with expanded sensitivity as a consequence perception and capacity into work intermodal stage attempt a inherent worldview for sending an extensive statistic about senses being recognition. Those nano sensors have potential as high delicate and exceptionally particular flag transduction stage for an incorporated unstable sensor framework. The relative dampness as noteworthy impact on time subordinate changes in differential aggregate diversions increments with the declines in relative moistness, cantilever redirection as an element of the affectability and relative stickiness, in low vapor analytes utilizing 4-MBA covered material expands affectability by $52 \%$.

\section{ACKNOWLEDGEMENTS}

This project is sponsored by DST New Delhi.

\section{REFERENCES}

1. Colton,r.j., and Russell, j. n, Science(2003)299, 1324

2. Hallowell, S. F., Talanta(2001) 54, 44

3. Fainberg, A., Science(1992)299.1531

4. Yinon, Y., (ed,),Counterterrorist detection of Explosives,Elsevier, Amsterdam,(2001)

5. Woodfin, R, L.,(ed), Trace chemical sensing of Explosives, John Wiley \& sons, Hoboken, New J ersey,(2001)

6. Cui, Y., et al., in Nanowiress and Nanobelts-materials, properties and Devices.

7. Thaysen, J., et al., Sens. Actuators, A(2001)92, 96

8. Yang, J. S., Swager, T M., J, Am, Chem, Soc. (1998) 120, 1186

9. Moore,D. S., Rev. Sci. Instrum. (2004) 75,9

10. Masunaga, K., et Al., Sensors and Actuators. B(2005)198.427

11. F capasso, J.,N. Munaday, D Iannuzzi and H.B.Chan." Casimir Forces and quantum electro dynamical Torques: Physics and nanomechanics", IEEE Journal of select topics in quantam electronics, Vol 13, 2007.

12. Ribu Mathew and A Ravi Sankar, "Design of a triangular platform piezoresistive affinity microcantilever sensor for biochemical sensing applications", IOP Publishing, J. Phys. D: Appl. Phys. Vol. 48.

13. Joseph C. Doll, Sung-Jin Park, and Beth L. Pruitt, "Design optimization of piezoresistive cantilevers for force sensing in air and water", American Institute of Physics, Journal of Applied Physics Vol. 106, 064310, 2009.

14. Hidetoshi Takahashi, Tetsuo Kan, Kiyoshi Matsumoto and Isao Shimoyama, "Simultaneous detection of particles and air flow with a NEMS piezoresistive cantilever", IOP Publishing, Meas. Sci. Technol. Vol. 24, 025107 (7pp), 2013.

15. Srinivasarao. Udara, Dr. P H S Tejo Murthy,"Characterization of MEMS/NEMS based Piezoresistive Cantilever Using Ominicant Experimentation ", Carmelight. 12(1): 144-155, 2016

16. Srinivasarao.Udara, Dr. P H S Tejo Murthy, "Fabrication and characterization of NEMS based piezoresistive cantilever for the detection of change in resistance with time at different experimental conditions using OmniCant”, IEEE Explore- Vol.09, Volume : No.13 (2016)

17. J. A. Harley and T. W. Kenny, " 1 /f Noise Considerations for the design and Optimization Cantilevers",vol 32. 2017

\section{AUTHORS PROFILE}

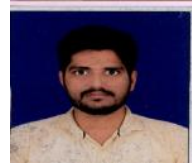

P.V.T Lokesh Kumar, belongs to, E.C.E Department, of Sir C.R.R College of Engineering, Eluru, A.P. He is working in the area of VLSI Design.

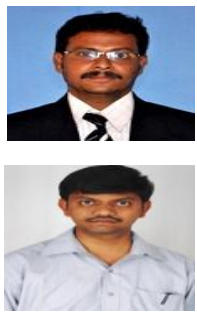

Dr.P.H.S Tejomurthy working as Professor in E.C.E Department of Sir C.R.R College of Engineering, Eluru, A.P. His areas of interest is VLSI Design.

Dharmireddy Ajay Kumar, working as an Assistan Professor, E.C.E Department of Sir C.R.R College of engineering, Eluru, A.P. His area of interest is VLSI Design. 